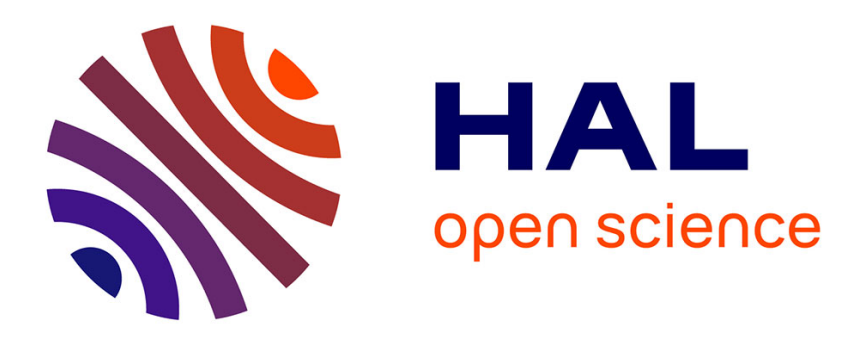

\title{
The Snoek Relaxation in Dilute Ternary bcc Alloys. A Review
}

H. Numakura, M. Koiwa

\section{To cite this version:}

H. Numakura, M. Koiwa. The Snoek Relaxation in Dilute Ternary bcc Alloys. A Review. Journal de Physique IV Proceedings, 1996, 06 (C8), pp.C8-97-C8-106. 10.1051/jp4:1996819 • jpa-00254627

\section{HAL Id: jpa-00254627 https://hal.science/jpa-00254627}

Submitted on 1 Jan 1996

HAL is a multi-disciplinary open access archive for the deposit and dissemination of scientific research documents, whether they are published or not. The documents may come from teaching and research institutions in France or abroad, or from public or private research centers.
L'archive ouverte pluridisciplinaire HAL, est destinée au dépôt et à la diffusion de documents scientifiques de niveau recherche, publiés ou non, émanant des établissements d'enseignement et de recherche français ou étrangers, des laboratoires publics ou privés. 


\title{
The Snoek Relaxation in Dilute Ternary bcc Alloys. A Review
}

\author{
H. Numakura and M. Koiwa \\ Department of Materials Science and Engineering, Kyoto University, Yoshida Hon-Machi, Sakyo-ku, \\ Kyoto 606-01, Japan
}

\begin{abstract}
The Snoek relaxation due to interstitial solutes in bcc metals is often affected markedly by the presence of a small amount of substitutional solute atoms. This effect is believed to originate from the interaction between the substitutional and interstitial solute atoms, or the $s-i$ interaction. This review summarizes first the experimental observations on the Snoek relaxation in various dilute alloys such as $\mathrm{Fe}-\mathrm{M}-\mathrm{C} / \mathrm{N}$ and $\mathrm{V} / \mathrm{Nb} / \mathrm{Ta}-\mathrm{M}-\mathrm{O} / \mathrm{N}$, and describes next the theoretical studies on the thermodynamics and kinetics of the relaxation. It is suggested from recent studies that careful examinations of the variation of the spectrum with solute concentrations are useful for quantitative characterization of the $s-i$ interaction.
\end{abstract}

\section{INTRODUCTION}

The Snoek relaxation due to interstitial solutes in bcc metals is one of the best understood phenomena among a number of anelastic effects in crystalline solids. In early $1950 \mathrm{~s}$, it was found that substitutional solutes significantly influenced the Snoek relaxation of $\mathrm{N}$ in Fe [1]. For example, the addition of $1 \% \mathrm{~V}$ strongly suppresses the ordinary Snoek peak of $\mathrm{N}$, and gives rise to a new, well-defined peak at a higher temperature. Since this discovery, a number of experiments have been made on various bcc alloys. In most of the alloy systems studied, distortion of the relaxation spectrum or an appearance of a new peak, often called an anomalous or abnormal Snoek peak, is recognized. Such effects must be due to an interaction between substitutional and interstitial solute atoms, which is referred to as the s-i interaction. If the interaction is attractive, interstitial solute atoms are bound, or trapped, to a substitutional atom. Jump processes of those interstitial atoms may be considerably modified, leading to relaxation peaks that have relaxation rates and magnitudes very different from the ordinary Snoek peak.

Early investigations on the effect of substitutional solutes were centred at $\mathrm{Fe}-\mathrm{M}-\mathrm{N}$ alloys, those of which reported by 1970 are reviewed by Fast [2]. Experimental studies were then extended to other systems, viz. Fe-M-C alloys and alloys based on group 5 transition metals (V, Nb and Ta), as summarized by Hasson and Arsenault [3] and by Nowick and Berry [4], both published in 1972. The latter althors gave a qualitative account of the observations on the basis of the general theory of anelastic relaxation $[5,6]$; some of the characteristic features can be reasonably explained in terms of local attractive interaction between substitutional and interstitial solute atoms (see also Nowick $[7,8]$ ). In the same period of time, Koiwa [9] developed an extended theory of relaxation kinetics in ternary alloys and analysed various aspects, i.e. reorientation relaxation in dilute alloys [10], hydrostatic relaxation [11], relaxation in B2-ordered alloys [12] and effects associated with substitutional atom pairs [13]. Recently, detailed experiments have been made on $\mathrm{O}$ in $\mathrm{Nb}-\mathrm{V}$ alloys [14] and $\mathrm{N}$ in $\mathrm{Fe}-\mathrm{Cr}$ alloys [15, 16], which allow quantitative characterization of the $\mathrm{s}-\mathrm{i}$ interaction. This paper gives a review of those experimental and theoretical studies of the Snoek relaxation in ternary bcc alloys. Citations are made mainly to articles not included in the earlier reviews. 


\section{EXPERIMENTAL STUDIES}

\section{$2.1 \mathrm{~N}$ in Fe alloys}

Figure 1 shows low-frequency internal friction spectra of dilute $\mathrm{Fe}-\mathrm{Cr}-\mathrm{N}$ alloys [15], which serve as an illustrious example of the effect of a substitutional element on the Snoek relaxation of N. By the addition of $\mathrm{Cr}$, the ordinary Snoek peak located at $300 \mathrm{~K}$ is reduced in magnitude and a new component appears at $320 \mathrm{~K}$. On further increase in the $\mathrm{Cr}$ concentration, another new component appears at a lower temperature. The concentration of $\mathrm{N}$ changes the magnitude of internal friction as a whole nearly proportionally, while the shape of the spectrum remains unchanged. Fe-Mn- $\mathrm{N}$ alloys are known to exhibit very similar features [2].

An extra component, or an interaction peak, at a high temperature has been found for a number of tertiary elements, e.g. Ti [17-20], V $[1,18,21-23], \mathrm{Cr}[21,24,25], \mathrm{Mn}[2,26], \mathrm{Mo}[1,21]$ and W [27], which are known to interact attractively with $\mathrm{N}$ in $\mathrm{Fe}$ [28]. For 3d elements, the position of the new peak is higher in the order $\mathrm{Mn}, \mathrm{Cr}, \mathrm{V}$ and $\mathrm{Ti}$, i.e. in a descending order of group number in periodic table. Solutes that are unlikely to attract $\mathrm{N}$ atoms have no marked influence, e.g. Ni and Co [29]. The high temperature peak is thus attributed to the reorientation of $\mathrm{N}$ atoms trapped to a substitutional solute atom. The low temperature component, on the other hand, is considered to be due to $\mathrm{N}$ atoms bound to a pair of substitutional solute atoms, for it begins to increase its height at relatively high substitutional solute concentrations, namely above 1 at.\%.

Early reports on $\mathrm{Fe}-\mathrm{Si}-\mathrm{N}$ alloys showed that these alloys exhibited a broad and complex internal friction spectrum [3], which appears to involve two or more extra components at temperatures above the ordinary Snoek peak. In a study using single crystals of an Fe-5.4 at.\% Si alloy [30], all the extra components were found to show the same anisotropy as the ordinary Snoek peak: the internal friction measured in torsion was much lower in a crystal whose axis is close to $\langle 100\rangle$ than the other close to $\langle 111\rangle$. This observation suggests that the lattice distortion produced by the defect(s) responsible for the extra components is similar in character to that associated with an isolated interstitial solute atom.

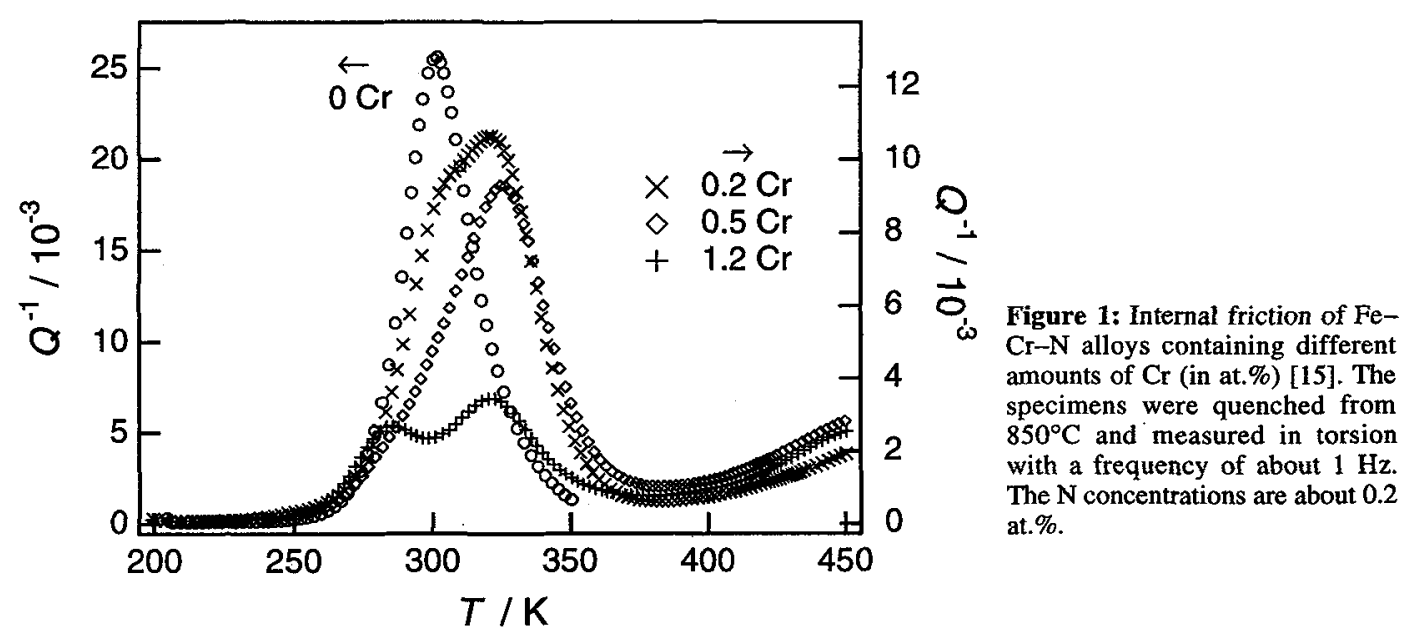

\section{$2.2 \mathrm{C}$ in Fe alloys}

The effects of substitutional solutes on the Snoek relaxation of $C$ appear very different from the case of $\mathrm{N}$. For additions less than a few atomic percent of a substitutional alloying element, the Snoek peak of $\mathrm{C}$ is decreased in height but no anomalous peak appears, as first reported for $0.5 \% \mathrm{~V}, \mathrm{Cr}, \mathrm{Mn}, \mathrm{Ni}$ and $\mathrm{Mo}$ by Wert in 1952 [31]. This trend has been confirmed by recent studies for $\mathrm{Cr}$ [32], $\mathrm{Mn}$ [33-35], P [36] and Si [35]. At the same time, however, a substantial broadening of the peak has come to be noticed, which was not clearly seen in Wert's work. The decrease in peak height by the addition of $\mathrm{Cr}$ and $\mathrm{Mn}$ was once attributed to the lowering of $C$ solubility [37], but it turned out that the solubility was not af- 
fected by the addition of $\mathrm{Mn}$ [33]. Thus it appears that extra components do exist in $\mathrm{Fe}-\mathrm{Mn}-\mathrm{C}$ alloys; the peak in the ternary alloys, smaller in magnitude and larger in width than in unalloyed Fe, probably consists of the ordinary and extra relaxations occurring at the same temperature range. The reduction in the relaxation strength can be interpreted as the effect of the substitutional solute atom on the tetragonal distortion around a $\mathrm{C}$ atom located at close-neighbour sites [38].

Alloys containing larger amounts of substitutional solutes often exhibit extra peaks at high temperatures. For substitutional solutes such as Al [39-41], Si [42, 43] and Ga [44], the Snoek peak of C diminishes and the high temperature component grows with the increase in the substitutional solute concentration. It is interesting to note that these elements, $\mathrm{Al}, \mathrm{Si}$ and $\mathrm{Ga}$, interact repulsively with $\mathrm{C}$ at high temperatures [45]. This apparently contradicts the picture of the interaction peak drawn for $\mathrm{N}$. However, even if the substitutional solutes do not trap $\mathrm{C}$ atoms, local lattice distortion around a substitutional solute atom may modify the migration behaviour of $C$ atoms in such a manner. This view is supported by the fact that the effect is observed only at relatively high concentrations of substitutional solutes, viz. above 2 or 3 at.\%. For the case of $\mathrm{V}$ as a substitutional element, on the other hand, an extra peak is observed at the low temperature side of the ordinary Snoek peak for concentrations above 1 at.\% [46]. Since the interaction of $V$ with $C$ is strongly attractive [45], this effect seems to be due to higher order clusters of substitutional-interstitial solute atoms, such as $\mathrm{s}-\mathrm{i}-\mathrm{s}$ complexes postulated for $\mathrm{Fe}-\mathrm{Cr}-\mathrm{N}$ and $\mathrm{Fe}-\mathrm{Mn}-\mathrm{N}$ alloys.

\subsection{Magnetic after-effect of $\mathrm{C}$ and $\mathrm{N}$ in Fe alloys}

Interstitial $\mathrm{C}$ and $\mathrm{N}$ in Fe cause a magnetic relaxation effect, called the Richter after-effect, which is an analogue of the Snoek effect in mechanical relaxation. Fundamental aspects of this phenomenon has been studied extensively from both experiment and theory (see, e.g. [47]). Investigations have also been made on the influence of substitutional solutes in ternary Fe alloys.

Graham and Wuttig [48] measured the magnetic disaccommodation of dilute $\mathrm{Fe}-\mathrm{M}-\mathrm{C}$ and $\mathrm{Fe}-$ $\mathrm{M}-\mathrm{N}$ alloys for $\mathrm{M}=\mathrm{Ti}, \mathrm{V}, \mathrm{Cr}$ and $\mathrm{Mn}$. They found a substantial influence of substitutional solutes on the after-effect due to $\mathrm{N}$ : the position of the relaxation maximum is shifted towards higher temperatures for $\mathrm{Mn}, \mathrm{Cr}$ and $\mathrm{V}$, the magnitude of the shift being larger in this order. In contrast, virtually no effects were observed on the relaxation behaviour of $C$. These results agree well with those of the internal friction studies described above. Moron and colleagues studied magnetic after-effect in dilute $\mathrm{Fe}-\mathrm{V}-\mathrm{C}$ [49], $\mathrm{Fe}-\mathrm{V}-\mathrm{N}[23,50]$ and dilute [51], as well as concentrated [52, 53], Fe-Al-C alloys. In all these experiments, several extra components were identified. Some of them were interpreted as contributions of $s-i$ pairs and others of $\mathrm{i}-\mathrm{i}$ pairs. Similar measurements have also been made on dilute $\mathrm{Fe}-\mathrm{Ti}-\mathrm{N}[54]$ and $\mathrm{Fe}-$ $\mathrm{Cr}-\mathrm{N}$ alloys [15]. Generally, the relaxation spectra in dilute ternary alloys show characteristic features observed in mechanical relaxation experiments on the same alloy systems.

\section{$2.4 \mathrm{~N}$ and $\mathrm{O}$ in $\mathrm{V}, \mathrm{Nb}$ and $\mathrm{Ta}$ alloys}

Investigations on the Snoek relaxation in alloys based on group 5 metals were first undertaken on $\mathrm{Nb}-$ $\mathrm{Zr}-\mathrm{O}$ alloys [55-57]. Despite the problem that the relaxation profiles were further complicated by the presence of $\mathrm{N}$ as a residual impurity, these investigations provided clear evidence for the $\mathrm{s}-\mathrm{i}$ interaction: the ordinary Snoek peak of $O$ is suppressed and new relaxations appear at higher temperatures [56, 57]. Szkopiak and Smith [58] investigated the Snoek relaxation of $\mathrm{N}$ and $\mathrm{O}$ in $\mathrm{Nb}-1$ at. $\% \mathrm{M}$ alloys for 13 elements, and observed subsidiary peaks due to the $s-i$ interaction for most elements. They discussed the nature of the interaction from various aspects such as atomic size, elastic modulus, chemical affinity, etc. Szkopiak extended this study to a concentrated $\mathrm{Nb}-\mathrm{Ta}(25 \%)$ alloy [59]. Interaction peaks have also been reported for $\mathrm{Ta}-\mathrm{Re}-\mathrm{N} / \mathrm{O}$ [60], $\mathrm{V}-\mathrm{Ti}-\mathrm{N} / \mathrm{O}$ and $\mathrm{V}-\mathrm{Al}-\mathrm{N} / \mathrm{O}$ alloys [61].

The experiments made on single crystals of ternary alloys $[56,62]$ provided particularly important information. For cubic crystals, the relaxation magnitudes in single crystals under uniaxial tensile and shear stress are given respectively by

$$
\begin{gathered}
\delta E^{-1}=\frac{1}{3} \delta S^{\prime \prime}+\delta S^{\prime}\left(\frac{1}{3}-\Gamma\right)+\delta S \Gamma \\
\delta G^{-1}=\delta S^{\prime} 2 \Gamma+\delta S(1-2 \Gamma),
\end{gathered}
$$

where $E$ stands for Young's modulus and $G$ the shear modulus, $\delta S^{\prime \prime}, \delta S^{\prime}$ and $\delta S$ are, respectively, the relaxation of the symmetrized compliances $S^{\prime \prime} . \equiv S_{11}+2 S_{12}, S^{\prime} \equiv 2\left(S_{11}-S_{12}\right)$ and $S \equiv S_{44}$, and 


$$
\Gamma=\gamma_{2}^{2} \gamma_{3}^{2}+\gamma_{3}^{2} \gamma_{1}^{2}+\gamma_{1}^{2} \gamma_{2}^{2}
$$

where $\gamma_{i}$ are direction cosines between the stress axis and the crystal axes. The orientation factor $\Gamma$ varies over the range from 0 for the stress in the $<100>$ direction to $1 / 3$ for $<111>$.

Miner et al. [56] measured internal friction of $\langle 100\rangle,\langle 110\rangle$ and $\langle 111\rangle$-oriented single crystals of $\mathrm{Nb}-1$ at.\% $\mathrm{Zr}-\mathrm{O}$ alloys by longitudinal vibration. The relaxation profile observed for the $\langle 100\rangle$ crystal was complex, which they interpreted as consisting of five components, viz. the contributions of $\mathrm{O}, \mathrm{Zr}-\mathrm{O}, \mathrm{O}-\mathrm{Zr}-\mathrm{O}, \mathrm{N}$ and $\mathrm{Zr}-\mathrm{N}$ (N was present as an impurity). In contrast, none of these relaxations was detected for the $\langle 111\rangle$ crystal. The anisotropy of the extra relaxation components is thus identical to that of the ordinary Snoek peak, in agreement with the result on Fe-Si-N alloys [30]. Referring to Eq. 1, the observation that $\delta E^{-1} \approx 0$ in the $<111>$ orientation $(\Gamma=1 / 3)$ implies that both $\delta S^{\prime \prime}$ and $\delta S$ are absent, or negligibly small. Sagues and Gibala [62] performed measurements on single crystals of Ta-Re-N and $\mathrm{Ta}-\mathrm{Re}-\mathrm{O}$ alloys under longitudinal stress and also under shear stress, and confirmed that the relaxation consisted only of $\delta S^{\prime \prime}$. According to the selection rule for anelastic relaxation [5], defects that can give rise to $\delta S^{\prime}$ are those of tetragonal or $<100>$ orthorhombic symmetry. The symmetry of an interstitialsubstitutional atom pair in a bcc crystal is tetragonal for the 1st neighbour configuration and $<110>$ orthorhombic for the 2 nd. Therefore, the results of the experiments on single crystals strongly suggest that the defects responsible for the extra relaxations are 1st neighbour s-i pairs. Nowick [63] pointed out, however, that relaxations due to 2 nd neighbour pairs may exhibit very similar anisotropy to that of a tetragonal defect, because the lattice distortion associated with an interstitial atom on a 2 nd neighbour site is expected to be virtually the same as that of an isolated interstitial atom.

Carlson and colleagues studied the interaction between interstitial $O$ and substitutional solutes in $\mathrm{Nb}-(0.24-10)$ at.\% V and $\mathrm{V}-0.5$ at.\% Nb $[14,64]$. They measured the Snoek relaxation of $\mathrm{O}$ and found a well-defined $s-i$ interaction peak in the $\mathrm{Nb}$-based alloys but not in the $\mathrm{V}$-based alloy; only the ordinary Snoek peak was observed in the latter. Figure 2 shows the relaxation profiles in $\mathrm{Nb}-0.24$ at.\% V alloys containing various amounts of $O$. With increasing the $O$ concentration, the height of the interaction peak located at $500 \mathrm{~K}$ first increases its height but saturates at a level close to the V concentration. On further increase in the $\mathrm{O}$ concentration, the ordinary Snoek peak begins to appear and then continues to grow. This observation indicates that each $\mathrm{V}$ atom traps approximately one $\mathrm{O}$ atom. Both the two peaks exhibit features of single relaxation, with the activation energy of the relaxation time being $1.16 \mathrm{eV}$ for the Snoek peak and $1.43 \mathrm{eV}$ for the interaction peak. The difference in the activation energies agrees with the V-O binding energy obtained from diffusion experiments [65]. They discussed the characteristics of the interaction peak in terms of elastic and chemical interactions; the presence of V-O interaction peak in $\mathrm{Nb}$ and the absence of $\mathrm{Nb}-\mathrm{O}$ interaction in $\mathrm{V}$ are consistent with the predictions from elastic and quasi-chemical models for the interaction.

The Snoek relaxation of $\mathrm{O}$ in $\mathrm{Nb}-\mathrm{Mo}$ and $\mathrm{Nb}-\mathrm{V}$ alloys has recently been studied over a wide range of substitutional solute concentrations from 1 to 50 at.\% [66].

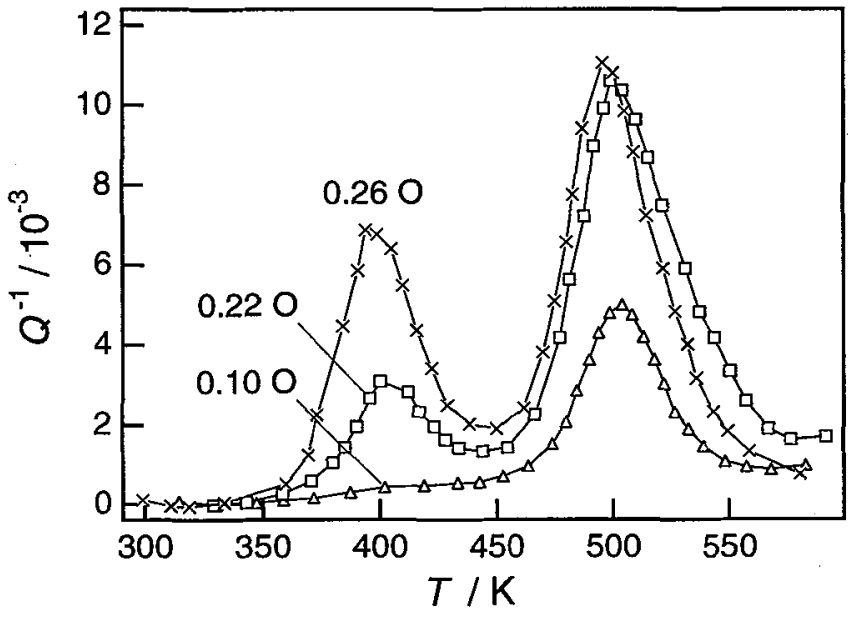

Figure 2: Internal friction of $\mathrm{Nb}-0.24$ at.\% V-O alloys measured in torsion with a frequency of about $0.25 \mathrm{~Hz}$. Oxygen concentrations are in at.\% [14]. (Courtesy of Metallurgical and Materials Transactions.) 


\section{THEORETICAL STUDIES}

\subsection{Simple theory - strongly bound model}

Atomistic mechanism of the relaxation of $s-i$ pairs in bcc alloys must be complex because 'in the bcc lattice an $\mathrm{s}-\mathrm{i}$ pair cannot reorient to an equivalent configuration by a single nearest neighbour jump of the interstitial atom' (Nowick and Berry [4]). Figure 3 shows the octahedral interstitial sites around a substitutional solute atom (a) and a schematic illustration of a potential energy profile for an interstitial solute atom (b). When an interstitial atom located at site $1 z$ is to move to site $1 x$, it should pass through site $2 y$, a second neighbour site from the substitutional solute atom, if only nearest neighbour jumps can occur. The 1 st and 2 nd neighbour s-i pairs, possessing different defect symmetries, are thus kinetically coupled in the relaxation process. The actual situation is more complicated since farther pairs must also be involved. Meijering [67] approached this problem by assuming interstitial solute atoms be confined in the 1st and 2nd neighbour shells and jumps occur only between neighbouring octahedral sites. He wrote down a set of rate equations for partial concentrations in each site and derived expressions for the relaxation rates and magnitudes. Nowick $[7,8]$ analysed the problem on the same assumptions but in more detail on the basis of the general theory of anelastic relaxation based on group theory $[5,6]$.

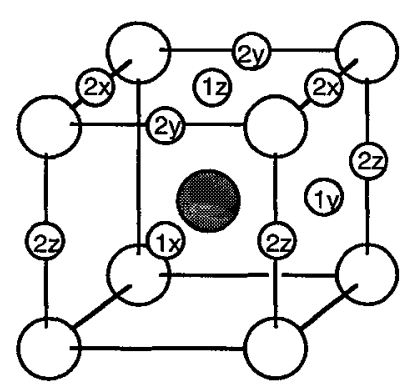

(a)

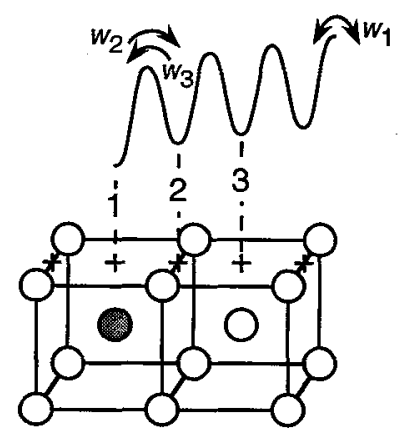

(b)

Figure 3: (a) Octahedral interstitial sites around a substitutional solute atom (shaded circle) in the bcc lattice. ' $1 x$ ' denotes, for example, a lst nearest neighbour site with the axis of tetragonal distortion in $x$-direction. (b) Potential energy profile for an interstitial solute atom.

According to the general theory, relaxation effects in a cubic crystal belong to one of the three 'normal modes' corresponding to the relaxations of the compliances $S^{\prime}, S^{\prime}$ and $S$. Using the irreducible representations of group theory, the three modes are referred to as $A_{1}, E$ and $T_{2}$. In the present problem, the 1 st neighbour (tetragonal) and 2 nd neighbour ( $<110>$ orthorhombic) s-i pairs give rise to one $A_{1}$ relaxation, two $E$ relaxations and one $T_{2}$ relaxation, as summarized in Table 1 . One may observe, therefore, four Debye peaks, provided that their magnitudes are not too small to be detected. The relaxation rates are given $[7,8]$ as

$$
\begin{gathered}
\tau_{A_{1}}^{-1}=4 w_{2}+2 w_{3} \\
\tau_{E \pm}^{-1}=2 w_{2}+w_{3} \pm\left[\left(2 w_{2}-w_{3}\right)^{2}+2 w_{2} w_{3}\right]^{1 / 2} \\
\tau_{T_{2}}^{-1}=2 w_{3},
\end{gathered}
$$

where $w_{2}$ and $w_{3}$ are the rate of the jump from a 1st to a 2 nd neighbour site and that of the reverse jump, respectively (see Fig. $3 b$ ). The ordinary Snoek relaxation belongs to $E$ mode, and its relaxation rate is

$$
\tau_{E, \text { Snoek }}^{-1}=6 w_{1}
$$


where $w_{1}$ is the jump rate free from the influence of substitutional solutes. It should be noted that relaxation rates cannot always be assigned to individual jumps even in this simplest model (e.g., Eq. 5).

Nowick and Berry [4] (see also Nowick [8]) discussed a limiting but probable case where the jump rate $w_{2}$ is much lower than $w_{3}$, and $w_{1}$ is in between. Figure 4 illustrates schematically the relaxation spectrum expected for such a case. In this approximation, Eqs 4 and 5 become

$$
\begin{gathered}
\tau_{A_{1}}^{-1} \approx 2 w_{3}, \\
\tau_{E+}^{-1} \approx 2 w_{3} ; \tau_{E-}^{-1} \approx 3 w_{2} .
\end{gathered}
$$

Therefore, one of the two $E$ relaxations, denoted by $E$-, would appear at the high temperature side of the ordinary Snoek peak, while the other $(E+)$ and relaxations $A_{1}$ and $T_{2}$ at the low temperature side with approximately equal relaxation rates. Concerning magnitudes, the strength of $E+$ relaxation is expected to be small because they are proportional to the concentration of the 2 nd neighbour pair, for which a relation

$$
\bar{C}_{2} / \bar{C}_{1}=2 w_{2} / w_{3}
$$

holds and is thus very low in this approximation. Here $\bar{C}_{1}$ and $\bar{C}_{2}$ are the equilibrium concentrations of the 1 st and 2 nd neighbour pairs. Relaxation $T_{2}$, which is due entirely to the interstitial atoms on the 2 nd neighbour sites, would be hardly detectable because $\bar{C}_{2}$ is low and, in addition, the shape factor is small [63]. Therefore, among the relaxations of shear compliances, the only relaxation actually observable would be $E$ - relaxation above the Snoek peak. This model thus explains the characteristic features observed in experiments: (1) an extra peak appears at higher temperatures than the ordinary Snoek peak, and (2) it is the relaxation of the compliance $\delta S^{\prime}$.

Table 1: Number of relaxations for tetragonal and $<110>$ orthorhombic defects in cubic crystals [8].

\begin{tabular}{lcccc}
\hline $\begin{array}{l}\text { Irreducible } \\
\text { representation }\end{array}$ & Relevant compliance & Defect & symmetry & $\begin{array}{c}\text { Total number of } \\
\text { relaxations }\end{array}$ \\
\cline { 3 - 4 } & & Tetragonal & $\begin{array}{c}<110> \\
\text { orthorhombic }\end{array}$ \\
\hline$A_{1}$ & $S^{\prime \prime}=S_{11}+2 S_{12}$ & 1 & 1 & $1^{\dagger}$ \\
$E$ & $S^{\prime}=2\left(S_{11}-S_{12}\right)$ & 1 & 1 & 2 \\
$T_{2}$ & $S=S_{44}$ & 0 & 1 & 1 \\
\hline
\end{tabular}

$\uparrow$ The relaxation rate of one of the two $S^{\prime \prime}$ relaxations is zero because of the conservation of the total number of defects.

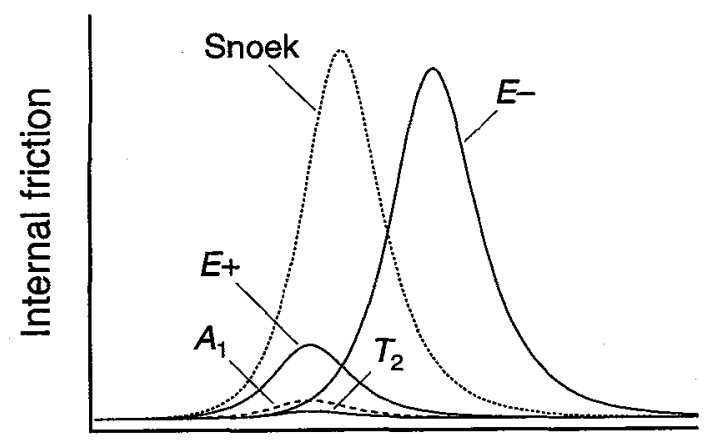

Temperature
Figure 4: Schematic internal friction spectrum expected from the strongly-bound model. 
Relaxation $A_{1}$, called a 'reaction mode' as contrasted to reorientation modes such as $E$ and $T_{2}$, occurs when more than one type of defect species are present and they transform to each other; a difference in volume between defect species leads to an increase in the number of some type of defects at the expense of others under hydrostatic stress [68]. This relaxation, $\delta S^{\prime \prime}$, does not appear in measurements under shear stress, but it does under tensile stress, with its magnitude being independent of the crystal orientation (see Eq. 1). The relaxation magnitude for the case of two reacting defect species is given [68] by

$$
\delta S^{\prime \prime}=\frac{\bar{C}_{\alpha} \bar{C}_{\beta}}{C_{\mathrm{t}}} \frac{V_{0}}{k T} \frac{1}{3}\left[\operatorname{tr}\left(\lambda^{\alpha}\right)-\operatorname{tr}\left(\lambda^{\beta}\right)\right]^{2}
$$

where $\bar{C}_{\alpha}$ and $\bar{C}_{\beta}$ are equilibrium concentrations of defects $\alpha$ and $\beta, C_{\mathrm{t}}$ is the total defect concentration, $V_{0}$ is the atomic volume, $k$ and $T$ have their usual meanings, and $\lambda^{\alpha}$ and $\lambda^{\beta}$ are the $\lambda$ tensors of the defects. This relaxation can be of substantial magnitude only when the concentrations of the two defect species are comparable and the volume dilatation produced by the defects are fairly different from each other. Estimation of the relaxation strength for the present case is difficult, however, because it requires a knowledge on the components of the $\lambda$ tensors of the 1st and 2 nd neighbour pairs. Here we make an order-of-magnitude estimate by letting, rather arbitrarily, the difference in the volume dilatation be 0.1 and $\bar{C}_{1}=50 \bar{C}_{2}$. Then, the relaxation strength is expressed approximately as

$$
\Delta \equiv \delta S^{\prime \prime} / S^{\prime \prime} \approx 0.1 C_{\mathrm{t}},
$$

with material constants of iron and $T=300 \mathrm{~K}$. For $C_{\mathrm{t}}=10^{-3}$, for example, $\Delta \approx 10^{-4}$, which can readily be measured by modern instruments. If it is observable with such a magnitude, experiments on the reaction mode, preferably using single crystals, may be useful for characterization of $s-i$ complexes.

\subsection{Extended theory}

By extending the approach of Meijering [67], Koiwa $[9,10]$ developed a theory of the Snoek relaxation in ternary alloys without the restriction that interstitial solute atoms are bound within the 2 nd neighbour distance. In the same manner as Meijering's treatment, the interstitial sites around a substitutional solute atom are classified into $1 x, 1 y, 1 z, 2 x, 2 y, 2 z$, and so forth, up to the 13th shell, according to the distance from the substitutional solute atom and the direction of the symmetry axis, and rate equations for partial concentrations (occupation probabilities of each site) are written with appropriate boundary conditions. Given the jump rates, which appear as coefficients, the set of simultaneous differential equations can be solved numerically in general, and analytically in simple cases. The anelastic response of the material is calculated from the variations of the partial concentrations under external stress.

An advantage of this theory is that a number of distinct jumps occurring at various distances from a substitutional solute atom can be treated explicitly. In principle, it is possible to derive analytical expressions for relaxation rates and magnitudes for such a general case on the basis of Nowick's theory. However, the mathematics involved must become extremely complicated as the number and the type of defect species are increased. In Koiwa's theory, on the other hand, the lattice distortion around an interstitial solute atom is assumed to be tetragonal for all sites, irrespective of the relative position to the substitutional solute atom. The effect of a substitutional atom on the shape factor is taken into account only for the 1st neighbour configuration: $\lambda_{1}-\lambda_{2}$ is treated as different from those for the other sites.

This theory shows that a relaxation spectrum can be decomposed in two ways, one into contributions of interstitial atoms in respective shells (decomposition I), and the other into Debye peaks, each corresponding to a normal mode of relaxation (decomposition II). It should be noted that each component in decomposition I cannot be expressed by a Debye function. In a simplified version of Koiwa's theory [10], where the influence of a substitutional atom is assumed to extend up to the 2 nd neighbour shell, there are three components in each decomposition: (I) the contributions of the 1st neighbour, 2nd neighbour and farther shells, (II) three Debye peaks of $E$ mode, two of which are those referred to as $E \pm$ in Nowick's analysis and the rest is the ordinary Snoek relaxation 1 . The behaviour of these relaxations was examined analytically and numerically, and it was confirmed that the rates of $E \pm$ relaxations do not obey the Arrhenius law [10], which can also be seen from Eq. 5 for the case of strong-binding.

Koiwa performed numerical calculations of relaxation spectra, in reference to the experimental observations in $\mathrm{Fe}-\mathrm{V}-\mathrm{N}$ and $\mathrm{Fe}-\mathrm{Mn}-\mathrm{N}$ alloys $[9,10]$. It was demonstrated that similar sets of site ener-

\footnotetext{
${ }^{1} T_{2}$ relaxation does not occur because all interstitials are assumed to produce simple tetragonal distortion.
} 
gies might lead to very different relaxation spectra, depending on the saddle point energies for the jumps out of or into trap sites. In the same framework, hydrostatic relaxation [11], relaxation in B2-ordered alloys [12] and effects of substitutional solute atom pairs [13] were studied. In the last paper, the low temperature peak observed in some alloys was suggested to be due to the reorientation of interstitials over the two equivalent configurations in an $s-i-s$ complex.

Estrin and Khachaturyan [69] presented a theory based on Green's function method for finding the relaxation rates due to defects in a crystal containing local lattice disturbances such as solute atoms or dislocations. Though they do not discuss the case of interstitial solute atoms in the bcc lattice, this theory can also be utilized to analyse the Snoek relaxation in bcc metals in the presence of substitutional solute atoms.

\subsection{Atomistic simulation}

Johnson, Dienes and Damask [70] performed a pioneering atomistic study on interstitial solute atoms in bcc metals; $\mathrm{C}$ in $\mathrm{Fe}$ and $\mathrm{N}$ in $\mathrm{V}$ were simulated using empirical pairwise interatomic potentials. They evaluated the magnitude of the lattice distortion around an interstitial solute atom, and the results were in reasonable agreement with the strength of the Snoek relaxation observed in experiments. The migration behaviour of interstitial atoms were also examined; diffusional motion of a $\mathrm{C}$ atom was found to occur from an octahedral site through a tetrahedral site as the saddle point and to a neighbouring octahedral site.

In Koiwa's kinetic theory, rates of all the jumps under consideration should be given for a relaxation spectrum to be calculated. In his own calculations, the attempt frequency was assumed to be equal for all the jumps, and migration energies were introduced as parameters. Such an energy profile cannot known a priori but is obtainable by atomistic simulation. Gouzou et al. [71] calculated the energy map for an interstitial solute atom in the vicinity of a substitutional solute atom using empirical potentials. With the potentials used, the activation energies for the jumps between the 1st and the 2nd neighbour sites (back and forth) are both lower than the ordinary jump. They also found that a direct jump between 1st neighbour sites, e.g. between $1 x$ and $1 y$, is possible via a circular path passing through a saddle point close to a 2 nd neighbour site $2 z$. The activation energy for the direct jump is approximately equal to that of the $1 \mathrm{st} \rightarrow 2$ nd jump. The theories quoted in the foregoing sections assume that jumps occur only between neighbouring octahedral sites. However, this result suggests that the possibility of direct jumps should not be excluded, even though the jump distance is much longer than the nearest-neighbour jump.

\section{RECENT PROGRESS}

\subsection{Lattice distortion associated with an s-i pair}

As described in Section 2.2, the experimental observation on Fe-Mn-C alloys can be interpreted as that the relaxation of $\mathrm{C}$ atoms bound to $\mathrm{Mn}$ atoms occurs at the same temperature range as the ordinary Snoek relaxation but with a substantially lower specific strength. In order to see how the relaxation strength can be reduced by the presence of substitutional solutes, evaluation of lattice distortion around an $s-i$ pair is required. Numakura et al. [38] extended the study of Johnson et al. to include a substitutional solute in the model, and calculated the distortion for various configurations of an $\mathrm{s}-\mathrm{i}$ pair. With the potentials used, the tetragonal distortion was found to be the smallest for the 1st neighbour pair, yielding a binding energy of $0.2 \mathrm{eV}$. The interatomic potentials adopted in the calculation were empirical pairwise functions used in previous investigations [70,71], which do not have sound physical basis, particularly the potential between the substitutional and interstitial solute atoms. The method is, however, quite general and applicable to various systems with any interatomic interaction scheme. Calculations based on models that better describe atomic interactions including interstitial solute atoms, e.g. the embedded-atom method [72], are expected to provide useful information.

\subsection{Quantitative characterization of the $s-i$ interaction in dilute $F e$ alloys}

Despite the development of theories for the thermodynamics and kinetics of relaxation, there has been little progress in the understanding of the nature of the $s-i$ interaction, particularly in iron alloys, in the last two decades. The present authors have undertaken a series of experimental investigations on dilute iron alloys in order to understand the interaction in a quantitative manner. The first work on $\mathrm{Fe}-\mathrm{Cr}-\mathrm{N}$ alloys [15] demonstrated that interaction energy is obtainable from a comparison of relaxation profiles observed in experiments and those calculated from the theory. The next work on the same alloy system but for very low solute concentrations enabled a more detailed analyses [16]. One can derive the binding and migration energies from the shape of the relaxation profile and its variation with the substitutional solute 
concentration. Within the framework of the simplified theory where the influence of a substitutional atom is assumed to extend to the 2nd neighbour shell [10], the observed relaxation spectra for $\mathrm{Cr}$ levels ranging from 0.05 to 0.2 at.\% can be satisfactorily reproduced, and the binding energy of a $\mathrm{Cr}-\mathrm{N}$ pair has been determined to be in the range between $0.16-0.18 \mathrm{eV}$.

\section{SUMMARY AND CONCLUDING REMARK}

Experimental and theoretical studies of the Snoek relaxation in ternary bcc alloys are reviewed. In early years of the research in this field, much effort was made on $\mathrm{Fe}-\mathrm{M}-\mathrm{N}$ and $\mathrm{Fe}-\mathrm{M}-\mathrm{C}$ alloys, then the behaviour of $\mathrm{N}$ and $\mathrm{O}$ in $\mathrm{V}, \mathrm{Nb}$ and Ta based alloys was studied extensively. Since quantitative understanding of the interaction between the solute atoms has not yet reached a satisfactory level, particularly in Fe-based alloys, further experimental investigations are desirable. The recent re-examination of $\mathrm{Fe}-$ $\mathrm{Cr}-\mathrm{N}$ alloys indicates that experiments using very dilute alloys are useful for the evaluation of $\mathrm{s}-\mathrm{i}$ interaction energies.

Historically, the interaction between $\mathrm{C}$ or $\mathrm{N}$ and alloying elements had been studied first for liquid iron and then for $\gamma$ iron [28]. For the liquid and $\gamma$ phases, the interaction parameter [28, 45], which is a thermodynamic measure of the interaction, is known to show a good correlation with the position of the alloying element in the periodic table, indicating that the interaction is mostly chemical in nature. On the other hand, the binding energy obtained from the analyses of the Snoek relaxation in ternary alloys is a kinetic measure, i.e. derived from the migration behaviour of interstitial solute atoms. It seems interesting to examine if the two measures conform to each other. Such an attempt has been made for $\mathrm{Nb}-\mathrm{V}-\mathrm{O}$ alloys [65], where the influences of $\mathrm{V}$ on the thermodynamic activity and on the diffusivity of $\mathrm{O}$ were compared. Parallel experiments of the effect of substitutional solutes on the thermodynamic properties and kinetic properties of interstitial solutes will shed more light on the nature of their atomic interaction.

\section{Acknowledgements}

The authors wish to thank Dr K. Ushioda and Mr N. Yoshinaga for discussions, and Metallurgical and Materials Transactions for granting permission to reproduce Figure 2. Financial supports from The Iron and Steel Institute of Japan and Kawasaki Steel 21st Century Foundation are gratefully acknowledged.

\section{References}

[1] Dijkstra, L. J., and Sladek, R. J., Trans. metall. Soc. AIME 197 (1953) 69-72.

[2] Fast, J. D., Gases in Metals, Philips Technical Library (N. V. Philips' Gloeilampenfabrieken, Eindhoven, 1976) Chapter 4.

[3] Hasson, D. F., and Arsenault, R. J., Treatise on Materials Science and Technology, H. Herman, Ed. (Academic, New York, 1972), Vol. 1, pp. 179-246.

[4] Nowick, A. S., and Berry, B. S., Anelastic Relaxation in Crystalline Solids (Academic, New York, 1972) Chapter 11.

[5] Nowick, A. S., and Heller, W. R., Adv. Phys. 14 (1965) 101-166.

[6] Nowick, A. S., Adv. Phys. 16 (1967) 1-47.

[7] Nowick, A. S., J. Phys. Chem. Solids 31 (1970) 1819-1826.

[8] Nowick, A. S., J. Phys. Chem. Solids 34 (1973) 1507-1521.

[9] Koiwa, M., Phil. Mag. 24 (1971) 81-106.

[10] Koiwa, M., Phil. Mag. 24 (1971) 107-122.

[11] Koiwa, M., Phil. Mag. 24 (1971) 539-554.

[12] Koiwa, M., Phil. Mag. 24 (1971) 799-814.

[13] Koiwa, M., Phil. Mag. 25 (1972) 701-714.

[14] Carlson, O. N., Indrawirawan, H., Owen, C. V., and Buck, O., Metall. Trans. A 18A (1987) 14151420 .

[15] Numakura, H., Miura, M., Matsumoto, H. and Koiwa, M., ISIJ Internat. 36 (1996) 290-299.

[16] Numakura, H., Mitani T., Taneike, M. and Koiwa, M., in preparation; to be submitted to ISIJ Internat.

[17] Szabó-Miszenti, G., Acta metall. 18 (1970) 477-484.

[18] Pope, M., Jones, D. M., and Jack, K. H., Proc. 5th Internat. Conf. on Internal Friction and Ultrasonic Attenuation in Crystalline Solids, D. Lenz and K. Lücke, Eds. (Springer, Berlin, 1975) pp. 266-275.

[19] He, K, and Hendry, A., Phil. Mag. A 66 (1992) 797-810.

[20] Hu, X. F., Ge, Q. L., and Wu, Z. L., Acta metall. 41 (1993) 1625-1632. 
[21] Soeno, K., and Tuchiya, M., Hitachi Review 16 (1967) 314-323.

[22] Welch, W. D., Jr, and Carpenter, S. H., Acta metall. 21 (1973) 1169-1179.

[23] Zgadzaj, J., Ilczuk, J., and Moron, J. W., J. Phys. (Paris) 42 (1981) C5, 835-840.

[24] Soeno, K., and Tuchiya, M., J. Jpn Inst. Metals 30 (1966) 1011-1017.

[25] Hotta, H., and Iwama, Y., Res. Rep. Nagoya Municipal Industrial Res. Inst. 39 (1968) 54-58.

[26] Kruk, A., Pietrzyk, J., and Kapusta, C., Scripta metall. 31 (1994) 1679-1683.

[27] Soeno, K., and Tuchiya, M., J. Jpn Inst. Metals 33 (1969) 786-790.

[28] Fromm, E., and Gebhardt, E., Gase und Kohlenstoff in Metallen (Springer, Berlin, 1976).

[29] Soeno, K., and Tuchiya, M., J. Jpn Inst. Metals 31 (1967) 305-310.

[30] Hashizume, H., and Sugeno, T., Jpn. J. appl. Phys. 6 (1967) 567-572.

[31] Wert, C., Trans. metall. Soc. AIME 194 (1952) 602-603.

[32] Yoshinaga, N., Ushioda, K., and Akisue, O., Oral presentation at the Spring Meeting of Japan Institute of Metals, Tokyo, April 1991.

[33] Saitoh, H., and Ushioda, K., ISIJ Internat. 29 (1989) 960-965.

[34] Yotsui, G., Master thesis (Graduate School of Engineering, Kyoto University, 1990).

[35] Ushioda, K., Yoshinaga, N., Saitoh, H., and Akisue, O., Defect Diff. Forum 95-98 (1993) 375380 .

[36] Saitoh, H., and Ushioda, K., Mater. Trans., JIM 34 (1993) 13-19.

[37] Kleemola, H. J., and Kuusisto, E. A., Scand. J. Metall. 5 (1976) 151-158.

[38] Numakura, H., Yotsui, G., and Koiwa, M., Acta metall. mater. 43 (1995) 705-714.

[39] Laxar, F. H., Frame, J. W., and Blickwede, D. J., Trans. ASM 53 (1961) 683-696.

[40] Jäniche, W., Brauner, J., and Heller, W., Arch. Eisenhüttenw. 37 (1966) 719-728.

[41] Hotta, H., and Iwama, Y., J. Jpn Inst. Metals 30 (1966) 406-411.

[42] Leak, D. A., and Leak, G. M., J. Iron Steel Inst. 189 (1958) 256-262.

[43] Borchers, H., and König, W., Arch. Eisenhüttenw. 34 (1963) 453-463.

[44] Astie, P., Peyrade, J.-P., and Garigue, J., C. R. Acad. Sci. Paris 275 (1972) Sér. C, 1177-1180.

[45] Nishizawa, T., Ishida, K., Ohtani, H., Kami, C. and Suwa, M., Scand. J. Metall. 20 (1991) 62-71.

[46] Sekine, H., Inoue, T., and Ogasawara, M., Jpn. J. appl. Phys. 6 (1967) 272.

[47] Rathenau, G. W., and de Vries, G., Magnetism and Metallurgy, A. E. Berkowitz and E. Kneller, Eds. (Academic, New York, 1973), Vol. 2, pp. 749-812.

[48] Graham, R. H., and Wuttig, M., Scripta metall. 3 (1969) 9-14.

[49] Haneczok, G., Ilczuk, J., Kuska, R., and Moron, J. W., Phys. stat. sol. (a) 33 (1976) 313-324.

[50] Zgadzaj, J., Moron, J. W., and Gigla, M., Arch. Nauki Mater. 3 (1983) 21-36.

[51] Kozlowski, L., Moron, J. W., and Rasek, J., Phys. stat. sol. (a) 13 (1972) 691-699.

[52] Wencek, H., and Moron, J. W., Acta phys. Pol. A51 (1977) 407-416.

[53] Wencek, H., and Moron, J. W., Phil. Mag. B 41 (1980) 611-618.

[54] Földeaki, M., Schwendemann, B., and Kronmüller, H., Z. Metallk. 77 (1986) 164-172.

[55] Bunn, P. M., Cummings, D. G., and Leavenworth, H. W., Jr, J. appl. Phys. 33 (1962) 3009-3013.

[56] Miner, R. E., Gibbons, D. F., and Gibala, R., Acta metall. 18 (1970) 419-428.

[57] Mosher, D., Dollins, C., and Wert, C., Acta metall. 18 (1970) 797-803.

[58] Szkopiak, Z. C., and Smith, J. T., J. Phys. D: Appl. Phys. 8 (1975) 1273-1284.

[59] Szkopiak, Z. C., Nuovo Cimento 33B (1976) 293-301.

[60] Sagues, A. A., and Gibala, R., Acta metall. 22 (1974) 1423-1432.

[61] Shikama, T., Ishino, S., Iokibe, H., and Mishima, Y., Proc. 6th Internat. Conf. on Internal Friction and Ultrasonic Attenuation in Solids, R. R. Hasiguti and N. Mikoshiba, Eds. (Univ. Tokyo Press, Tokyo, 1977) pp. 459-463.

[62] Sagues, A. A., and Gibala, R., Proc. 5th Internat. Conf. on Internal Friction and Ultrasonic Attenuation in Crystalline Solids, D. Lenz and K. Lücke, Eds. (Springer, Berlin, 1975) pp. 289-297.

[63] Nowick, A. S., Scripta metall. 7 (1973) 289-294.

[64] Indrawirawan, H., Buck, O., and Carlson, O. N., Phys. stat. sol. (a) 104 (1987) 443-451.

[65] Park, J., and Altstetter, C. J., Acta metall. 34 (1986) 2217-2224.

[66] Kushnareva, N. P., and Snejko, S. E., J. Alloys Compounds 211/212 (1994) 75-79.

[67] Meijering, J. L., Mét. Corros. Ind. 37 (1961) 107-111.

[68] Nowick, A. S., J. chem. Phys. 53 (1970) 2066-2074.

[69] Estrin. Yu. Z., and Khachaturyan, A. G., Phys. stat. sol. (b) 53 (1972) 613-622.

[70] Johnson, R. A., Dienes, G. J., and Damask, A. C., Acta metall. 12 (1964) 1215-1224.

[71] Gouzou, J., Wégria, J., and Habraken, L., C. R. M. Metall. Rep. 33 (1972) 65-71.

[72] Daw, M. S., Foiles, S. M., and Baskes, M. I., Mater. Sci. Rep. 9 (1993) 251-310. 